\title{
A trajetória do ilustrado Manuel Ferreira da Câmara em sua "fase européia" (1783-1800)*
}

Alex Gonçalves Varela*

O objetivo deste trabalho consiste em analisar o processo de formação e especialização científica do personagem no âmbito da política estatal de renovação culturalcientífica do governo de Dona Maria I. Essa política buscava criar um novo corpo de funcionários ilustrados para fornecer pessoal à burocracia estatal e formar uma "elite do conhecimento" interessada na exploração do mundo natural do Reino e das colônias. Analisar-se-ão três momentos desse processo: os estudos na Faculdade de Filosofia da Universidade de Coimbra; a entrada para a Academia Real das Ciências de Lisboa; e a viagem científica pelos principais centros de mineração da Europa Central e Setentrional.

Palavras-chave: Manuel Ferreira da Câmara - Ilustração Luso-Americana - Academia Real das Ciências de Lisboa

* Artigo recebido em novembro de 2006 e aprovado para publicação em junho de 2007.

** Bolsista PCI de pós-doutorado do Museu de Astronomia e Ciências Afins. O artigo foi elaborado no âmbito do projeto "A Constituição de Redes de Informação Científica no Império Português (1780-1823)", desenvolvido na Coordenação de História da Ciência do MAST, sob a supervisão da Dra. Heloísa Meireles Gesteira. E-mail: alexvarelarj@terra.com.br 
The Trajectory of the illustrious Manuel Ferreira da Câmara in its "European Phase" (1783-1800)

Manuel Ferreira da Câmara is known to history as a statesman and politician. His historical trajectory, however, was characterized by the association of his political interests with his work as a scholar of the natural sciences. The objective of the present article is to analyze Ferreira da Câmara's formation as a scientist within the context of the state policies of cultural and scientific renewal established during the reign of Dona Maria I. These policies sought to create a new corps of enlightened civil servants who would staff the state bureaucracies and form an "educated elite" which would be interested in the exploration of natural phenomena in Portugal and its colonies. We analyze three moments in this process: Ferreira da Câmara's studies at the Faculdade de Filosofia da Universidade de Coimbra, his entry into the Academia Real das Ciências de Lisboa and his scientific voyage to the main centers of mineral production in Central and Southern Europe.

Keywords: Manuel Ferreira da Câmara - Luso-America Enlightenment - Academia Real das Ciências de Lisboa

\section{La trajectoire de Manuel Ferreira da Câmara pendant sa "période euro- péenne" (1783-1800)}

Le but de cet article est d'analyser le processus de formation et de spécialisation scientifiques de Manuel Ferreira da Câmara dans le contexte de la politique de renouvellement culturel et scientifique du gouvernement de Dona Maria I. Cette politique cherchait à créer un nouveau corps de fonctionnaires illustrés afin de consolider la bureaucratie de l'État et former une "élite de connaisseurs "ntéressée à l'exploitation du monde naturel du Royaume et des colonies. On analyse ici trois moments de ce processus: les études à l'Université de Coimbra; la nomination à l'Académie Royale des Sciences de Lisbonne; le voyage scientifique aux principaux centres de mines de l'Europe Centrale et Septentrionale.

Mots-clés: Manuel Ferreira da Câmara - Éclaircissement Luso-Américain - Academie Royale des Sciences de Lisbonne

A presença do ilustrado Manuel Ferreira da Câmara Bethencourt Aguiar e Sá na bibliografia especializada se dá em função do seu perfil de político, evidenciando a sua atuação enquanto estadista e parlamentar. Tais análises dão relevância ao desempenho do personagem no período da Independência, como deputado na Assembléia Nacional Constituinte de 1823 e como senador por Minas Gerais no período de 1827 a 1835. São estudos, portanto, que enfatizam exclusivamente o viés político de sua trajetória histórica. ${ }^{1}$

\footnotetext{
${ }^{1}$ Como exemplo dessa historiografia que destaca o perfil político de Manuel Ferreira da Câmara, ver J. F. Sigaud, "Dr. Manoel Ferreira da Câmara de Bittancourt e Sá", Revista do Instituto Histórico e Geográfico Brasileiro, Rio de Janeiro, tomo IV, p. 515-518, 1842.
} 
No entanto, Manuel Ferreira da Câmara notabilizou-se não apenas como homem público, mas também como um estudioso e pesquisador do mundo natural. Em sua trajetória histórica, a face de naturalista e os interesses políticos são indissociáveis, fato que caracteriza o homem ilustrado do século XVIII. ${ }^{2}$ Não são duas carreiras diferentes ou sucessivas, mas dois perfis de uma mesma trajetória de vida que não podem ser de forma alguma cindidos: $\mathrm{o}$ de estudioso das ciências naturais e o de homem público. Portanto, há lacunas que estimulam a reflexão sobre o personagem em novas direções.

O que também se pode observar, após um levantamento preliminar, é a existência de pouca bibliografia sobre a trajetória de vida desse personagem, em que ganham destaque a biografia de Marcos Carneiro de Mendonça ${ }^{3}$ e alguns artigos curtos, como os de O. H. Leonardos ${ }^{4}$ V V. Leinz. ${ }^{5}$ Somente nos últimos anos, em razão do resgate da história das ciências na América Latina sob novo arcabouço historiográfico, é que Câmara voltou a ser objeto de estudo, destacando-se os trabalhos de Manuel Serrano Pinto ${ }^{6}$ e Silvia Figueirôa. ${ }^{7}$

Contudo, falta ainda um estudo contextualizado da vida e obra do naturalista inserido no debate mais amplo sobre a história e a historiografia das ciências no Império Português, reconhecendo-se o peso do reformismo Ilustrado e os variados papéis profissionais que desempenhou. Como argumentou

\footnotetext{
${ }^{2}$ A associação entre interesses científicos e políticos é bastante clara na trajetória histórica dos homens da Ilustração. Como exemplo, mencionamos o francês Antoine Laurent Lavoisier (1743-1794), que atuava ao mesmo tempo como químico e Ferme Générale, coletor de impostos do Antigo Regime francês. Ver Bernardette Bensaude-Vincent, "Lavoisier: uma Revolução Científica", in: Michel Serres (Dir.), Elementos para uma história das ciências, Lisboa, Terramar, 1996.

${ }^{3}$ Marcos Carneiro de Mendonça, O Intendente Câmara. Manuel Ferreira da Câmara Bethencourt e Sá, Intendente Geral das Minas e dos Diamantes, 1764-1835, São Paulo, Companhia Editora Nacional, 1958.

${ }^{4}$ O. H. Leonardos, “O Intendente Câmara”, Engenharia, mineração e metalurgia, Rio de Janeiro, v. 36, n. 215, 1962, p. 226-228.

${ }^{5}$ V. Leinz, "Manoel Ferreira da Câmara e José Bonifácio de Andrada e Silva ingressando na escola de Minas de Freiberg", Engenharia, mineração e metalurgia, Rio de Janeiro, v. 38, n. 227, 1963, p. 213-215.

${ }^{6}$ Manuel Serrano Pinto, "A experiência européia de Manoel Ferreira da Câmara e seus reflexos no Brasil - algumas notas”, in: S. F. de M. Figueirôa \& M. M. Lopes (orgs.). Geological Sciences in Latin America. Scientifics relations and exchanges, Campinas, São Paulo, Unicamp/ IG, 1994, p. 245-264.

${ }^{7}$ Silvia F. de M. Figueirôa, “Um 'Pensionário Fiel de Sua Majestade’: Manuel Ferreira da Câmara, 1764-1835”, in: Diana Soto Arango et al. (orgs.), Científicos Criollos e Ilustración, Madrid, Ediciones Doce Calles, Colciencias, Rudecolombia, 1999.
} 
Silvia Figueirôa ${ }^{8}$ a supremacia da história política e administrativa, aliada às concepções historiográficas sobre a carência de atividades científicas locais, levou, de forma conjunta, à falta de um lugar na história e ao tratamento de exceção para o que foi efetivamente realizado no campo científico, alimentando um círculo gerador de homens excepcionais e de seus contemporâneos pouco lembrados.

Neste trabalho, temos como objetivo analisar o processo de formação e especialização do ilustrado, dentro da política estatal de renovação culturalcientífica do governo mariano, que tinha o intuito de criar um novo corpo de funcionários ilustrados para formar, ao mesmo tempo, a burocracia estatal e uma "elite do conhecimento" interessada na exploração do mundo natural do Reino e das colônias. Três momentos desse processo serão destacados: os estudos na Faculdade de Filosofia da Universidade de Coimbra; a entrada para a Academia Real das Ciências de Lisboa; e a viagem científica pelos principais centros de mineração da Europa Central e Setentrional.

\section{A formação em Leis e Filosofia Natural na Universidade de Coimbra}

Manuel Ferreira da Câmara Bethencourt Aguiar e Sá, filho de Francisca Antônia Xavier de Bethencourt e Sá e do tenente Bernardino Rodrigues Cardoso, nasceu em Minas Gerais, muito provavelmente em Santo Antônio de Itacambira, em territórios da Demarcação Diamantina, por volta de 1764.

A família de Câmara possuía status social elevado. Seu pai era tenente, e sua mãe provinha de uma família de muitas posses, com fortuna ligada às minas de ouro. Dois dos seus tios maternos haviam-se formado em Coimbra, em Cânones, tendo um deles chegado a desembargador. ${ }^{9}$ Após a mudança dos pais da região de Minas Gerais para a Bahia, ele e o irmão, José de Sá Bethencourt e Accioli, ${ }^{10}$ foram educados por uma tia - proprietária de minas de ouro - em Caeté, Minas Gerais, região aurífera até a atualidade.

\footnotetext{
${ }^{8}$ Ibidem, p. 214.

${ }^{9}$ O status social elevado da família de Câmara permite estabelecer uma comparação com o estudioso José Bonifácio de Andrada e Silva, cujo pai possuía uma das maiores fortunas de Santos. Ver: Alex Gonçalves Varela, "Juro-lhe Pela Honra de Bom Vassalo e Bom Português": Análise das Memórias Científicas de José Bonifácio de Andrada e Silva (1780-1819), São Paulo, Annablume, 2006.

${ }^{10}$ Sobre José de Sá Bethencourt e Accioli, ver o trabalho de: Clarete Paranhos da Silva, Garimpando memórias: as ciências mineralógicas e geológicas no Brasil na transição do século XVIII para o XIX, Tese (Doutorado em Ciências da Terra), Universidade Estadual de Campinas, Campinas, 2004.
} 
Como todos os membros da elite colonial que desejavam realizar um curso superior, uma vez que na América Portuguesa não havia instituições universitárias, Câmara viajou para a metrópole com o intuito de se matricular na Universidade de Coimbra. A sua chegada a Portugal coincidiu com o período de "abertura" às novas idéias em razão das iniciativas do Marquês de Pombal.

Câmara matriculou-se em Coimbra no ano de 1783 no curso de Leis. No ano seguinte, passou a cursar também o de Filosofia Natural. Tornou-se bacharel em Leis e Filosofia em 1787 e obteve o diploma em junho de $1788 .{ }^{11}$ Nesse período, juntou-se às elites cultas da metrópole que também ali estudavam; todos leram as mesmas obras e receberam a mesma formação. ${ }^{12}$

As aulas na reformada Universidade de Coimbra, sobretudo no curso de Filosofia, onde lecionavam homens como Domenico Vandelli, funcionaram como um pólo de divulgação do novo conceito de ciência - uma ciência vocacionada para a aplicação prática e para o progresso das atividades econômicas, cujo objetivo último era a criação das condições necessárias para o bem-estar e para a felicidade dos povos. Essa nova visão da ciência influenciou as gerações que entre o final do século XVIII e o início do século XIX passaram pela instituição. ${ }^{13}$

Foi no espaço universitário que Câmara estabeleceu os primeiros contatos com aquele que seria o seu principal interlocutor, o naturalista José Bonifácio de Andrada e Silva. Os dois tiveram formação e trajetória de vida muito

${ }^{11}$ No período de 1772-1822, 866 brasileiros se formaram em Coimbra, cerca da metade deles em Leis e Matemática ou Ciências Naturais, acumulando as duas ou três especialidades. Ver: Francisco de Morais, Lista dos estudantes brasileiros na Universidade de Coimbra, Anais da Biblioteca Nacional, Rio de Janeiro, v. 62, p. 141. Vale salientar ainda que Câmara compunha a elite da Capitania de Minas Gerais, que foi titulada por Coimbra e que seria arregimentada no serviço do Estado no período mencionado. Caio C. Boschi, "A Universidade de Coimbra e a Formação Intelectual das Elites Mineiras Coloniais”, Estudos Históricos, Rio de Janeiro, vol. 4, n. 7, p. 100-111, 1991.

${ }^{12}$ José Bonifácio e Câmara comporiam, no período da Independência, aquilo que Lúcia Neves chamou de "elite coimbrã", a facção mais conservadora da elite brasileira, que partilhava da idéia de um grande império luso-americano, característico da geração de 1790, da qual faziam parte Lúcia Maria Bastos Pereira das Neves \& Humberto Fernandes Machado. O Império do Brasil. Rio de Janeiro, Nova Fronteira, 1999, 502 p. Ver também: Kenneth Maxwell. A geração de 1790 e a idéia do Império luso-brasileiro, in: Kenneth Maxwell. Chocolate, piratas e outros malandros. Ensaios tropicais. Rio de Janeiro, Paz e Terra, 1999; Maria Beatriz Nizza da Silva. A cultura luso-brasileira: da reforma da universidade à Independência do Brasil, Lisboa, Editorial Estampa, 1999.

${ }^{13}$ Ana Maria Cardoso de Matos, Ciência, tecnologia e desenvolvimento industrial no Portugal Oitocentista. O Caso dos Lanifícios do Alentejo, Lisboa, Editorial Estampa, 1998. 
parecidas. Após o término dos estudos em Coimbra, foram recrutados pela política portuguesa, que visava privilegiar as carreiras públicas de indivíduos nascidos na América. ${ }^{14}$ Tal fato demonstra o papel central da Universidade como formadora de recursos humanos qualificados para o aparelho estatal, ou seja, a preparação e o treinamento de uma elite luso-americana, modernizadora e ilustrada, que se colocaria a favor de uma política de Estado, cujo objetivo era regenerar o Império Português. ${ }^{15}$

\section{Aentrada para a Academia Real das Ciências de Lisboa}

Após a conclusão do curso superior em Coimbra, Câmara permaneceu em Portugal, sendo eleito membro da Academia Real das Ciências de Lisboa no ano de 1789. A Academia foi um centro aglutinador do ideário reformista do governo de D. Maria $\mathrm{I}^{16}$ e um locus de debate científico e da gestão da política colonial voltada para a exploração do mundo natural. ${ }^{17}$ Neste espaço, Câmara integrou-se ao subgrupo de naturalistas, ${ }^{18}$ que tinha como personagem principal o italiano Domenico Vandelli. ${ }^{19}$

${ }^{14}$ Íris Kantor, "Ciência e Império: Trajetórias de Ilustrados Lusoamericanos na Segunda Metade do Século XVIII”, in: Laboratório do Mundo. Idéias e Saberes do Século XVIII, São Paulo, Pinacoteca do Estado, Imprensa Oficial, 2004, p. 248.

${ }^{15}$ Caio C. Boschi, op. cit., p. 108; Ana Rosa Cloclet da Silva, "A Formação do Homem-Público no Portugal Setecentista: 1750-1777”, Revista Intellectus, Rio de Janeiro, ano 2, vol.2, 2003, p. 27.

${ }^{16} \mathrm{O}$ ápice da Ilustração portuguesa ocorreu no momento em que D. Maria I assumiu o trono, dando início ao que se convencionou chamar de "viradeira". Esse período caracterizou-se pelo reforço das práticas ilustradas de caráter pragmático-científico, que já vinham sendo fomentadas desde o período do consulado pombalino, durante o reinado anterior de D. José I. Ver: Fernando Novais, Portugale Brasil na crise do antigo sistema colonial (1777-1808), 6.ed., São Paulo, Hucitec, 1995; Francisco José Calazans Falcon, A época pombalina. Política econômica e monarquia ilustrada, 2.ed., São Paulo, Editora Ática, 1993.

${ }^{17}$ Oswaldo Munteal Filho, Uma sinfonia para o novo mundo: a Academia Real das Ciências de Lisboa e os caminhos da Ilustração luso-brasileira na crise do antigo sistema colonial, Tese de doutorado, Departamento de História, UFRJ, Rio de Janeiro, 1998.

${ }^{18}$ Oswaldo Munteal Filho, Domenico Vandelli no anfiteatro da natureza: a cultura científica do reformismo ilustrado português na crise do antigo sistema colonial (1779-1808), Dissertação de mestrado, Departamento de História, PUC-Rio, Rio de Janeiro, 1993.

${ }^{19} \mathrm{O}$ paduano Domenico Vandelli, no âmbito da Academia, adotou o ecletismo do reformismo ilustrado, pelo qual se posicionou em favor de algumas idéias do mercantilismo, adotando tanto os princípios fisiocráticos italianos e franceses como os princípios da economia clássica inglesa. Fernando A. Novais, "O reformismo ilustrado luso-brasileiro: alguns aspectos", Revista Brasileira de História, São Paulo, n. 7, 1984. 
Vandelli defendia a realização de um profundo inventário da natureza do Reino e das colônias, que seria estudada nos estabelecimentos científicos lisboetas, como os Jardins Botânicos e Museus de História Natural, entre outros, por meio dos métodos de classificação e dissecação. Ele teve uma atuação fundamental para a criação do "complexo museológico da Ajuda", ${ }^{20}$ que centralizava o vasto projeto de se produzir uma "história natural do Reino e das colônias".

O conhecimento da natureza estava diretamente relacionado à política fomentista do governo mariano e joanino, uma vez que se acreditava que as produções naturais da colônia ajudariam na recuperação econômica do Reino e se valorizava a agricultura, baseada nas práticas científicas de orientação pragmática, que via na natureza tropical uma fonte geradora de riqueza. A natureza americana, portanto, deveria ser cientificamente conhecida e explorada, pois contribuiria para o processo de industrialização português.

$\mathrm{Na}$ Academia, Câmara publicou diversas memórias científicas. A primeira dissertação, apresentada a 13 de maio de 1789, intitula-se Ensaio de Descrição Física e Econômica da Comarca de Ilhéus na América. O estudo divide-se em três partes, e logo na sua introdução, Câmara destaca o caráter útil do seu trabalho e, portanto, moderno: "O desejo de ser útil à minha nação me faz ser atrevido, e dar-me-ei por muito feliz se das minhas tais quais observações puder resultar algum bem à pátria, ou à humanidade". ${ }^{21}$

O pragmatismo e o utilitarismo são duas características presentes na prática científica do naturalista Manuel Ferreira da Câmara, como de outros estudiosos luso-americanos. ${ }^{22}$ Contudo, tais atributos não foram exclusivos da Ilustração luso-americana. As ciências naturais modernas de perfil baconiano, em sua essência, pressupunham a utilidade e o bem-estar dos homens. Para Bacon, a história natural era uma forma de investigação destinada a registrar o conhecimento do mundo para o uso e o aperfeiçoamento da humanidade. E

${ }^{20}$ João Carlos Pires Brigola, Coleções, Gabinetes e Museus em Portugal no século XVIII, Lisboa, Fundação Calouste Gulbenkian, Fundação para a Ciência e a Tecnologia, Ministério da Ciência e do Ensino Superior, 2003.

${ }^{21}$ Manuel Ferreira da Câmara, Ensaio de Descrição Física, e Econômica da Comarca dos Ithéus na América (1789), in: Memórias Econômicas da Academia Real das Ciências de Lisboa, Para o Adiantamento da Agricultura, das Artes, e da Indústria em Portugal, e Suas Conquistas (1789-1815), Tomo I, Lisboa, Banco de Portugal, 1990, p. 229.

${ }^{22} \mathrm{O}$ historiador Ronald Raminelli considerou que o naturalista Alexandre Rodrigues Ferreira não estava conectado aos avanços da ciência no século XVIII porque suas memórias científicas continham dados utilitários. O autor deixou assim transparecer a falta de conhecimento sobre a prática da História Natural no Setecentos. O utilitarismo era uma das características centrais da História Natural no Setecentos. Ronald Raminelli, "Ciência e Colonização - Viagem Filosófica de Alexandre Rodrigues Ferreira”, Tempo, Rio de Janeiro, v. 3, n. 6, p. 164, dezembro de 1998. 
será na direção da procura da utilidade que o estudo da natureza convergirá no século XVIII, firmando-se, assim, como a crítica do conhecimento diletante. Novos museus, jardins botânicos, academias científicas e coleções tomaram o lugar dos gabinetes de curiosidades e dos jardins consagrados exclusivamente ao deleite aristocrático. A História Natural que se estabeleceu nas instituições européias, como, por exemplo, nas francesas da última década do século XVIII, era marcada por forte utilitarismo. ${ }^{23}$

Seguindo as considerações da historiadora das ciências Maria Margaret Lopes, ${ }^{24}$ vários trabalhos sobre o tema da Ilustração luso-americana do Setecentos têm sido produzidos sob um enfoque que prioriza as conotações político-econômicas do processo, o que deixa de lado a produção culturalcientífica do período, não incorporando os entendimentos de ciências efetivamente veiculados e postos em prática para alicerçar os processos modernizadores de Portugal e do Ultramar. Na maioria dos casos, de acordo com as considerações da mencionada historiadora das ciências, reduz-se todo o movimento do Império português de adesão às ciências modernas a apenas "utilitarismos", "pragmatismos", "imediatismos", de conotações pejorativas. Ademais, reforçam-se visões que partilham as noções de "atraso" científico português, e conseqüentemente brasileiro, e sua inviabilidade de participação nas ciências européias do período.

Ainda com esse foco, observa-se que o termo nação traduz o pertencimento à monarquia portuguesa, revelando o grau de envolvimento de Câmara na execução do programa político-reformista do governo mariano. ${ }^{25}$ No ano de 1797 ou 1798, o ministro da Marinha e Ultramar, Dom Rodrigo

${ }^{23}$ Lorelai Brilhante Kury, "Entre Utopia e Pragmatismo: a História Natural no Iluminismo Tardio”, in: Luiz Carlos Soares (org.), Da Revolução Científica à Big (Business) Science, São Paulo, Hucitec, Rio de Janeiro, Eduff, 2001, p. 142-143.

${ }^{24}$ Maria Margaret Lopes, Silvia F. de M. Figueirôa, Relatório cientifico final do projeto emergência e consolidação das ciências naturais no Brasil (1770-1870), Campinas, DGAE/IGE/ Unicamp, 2003, mimeogr., p. 50.

${ }^{25}$ A idéia de nação como o sentimento de pertencimento à Monarquia Portuguesa aparecia em textos de outros ilustrados reformistas nascidos na Colônia e agentes ativos na execução da política de edificação do Império luso-brasileiro. Afinal, no sistema então vigente não havia dúvidas quanto ao pertencimento de todos os "nascidos nas quatro partes do mundo português" à Monarquia lusa, nem tampouco se podia negar que todos eram descendentes do povo português emigrado para o Brasil. Sobre tal discussão, ver: Maria de Lourdes Viana Lyra, A utopia do poderoso império: Portugal e Brasil - Bastidores da política, 1798-1822, Rio de Janeiro, Sette Letras, 1994; Maria de Lourdes Lyra, "Pátria do cidadão: a concepção de pátria/nação em Frei Caneca, Revista Brasileira de História, São Paulo, vol. 18, n. 36, 1998; Guilherme Pereira das Neves, "Do Império Luso-Brasileiro ao Império do Brasil (1789-1822)", Ler história, Lisboa, v. 27-28, 1995, p. 75-102; Ana Rosa Cloclet da Silva, Construção da nação e escravidão no pensamento de José Bonifácio, 1783-1823, São Paulo, FAPESP, Campinas, Editora da Unicamp, 1999. 
de Sousa Coutinho, apresentou a Memória Sobre o Melhoramento dos Domínios de Sua Majestade na América, lançando assim o "programa de reformas", cujo propósito principal era a regeneração do Império Português. No programa, Portugal passava a ser concebido como o centro das decisões políticas e das relações comerciais, enquanto os domínios no ultramar passariam a constituir "províncias da Monarquia", reunidas todas num "mesmo sistema administrativo" e "sujeitas aos mesmos usos e costumes". O objetivo fundamental era o resguardo do sacrossanto princípio da unidade, primeira base da Monarquia que se deve conservar com o maior ciúme a fim de que o português nascido nas quatro partes do mundo português se julgue somente português e não se lembre senão da glória e grandeza da Monarquia, a que tem a fortuna de pertencer. ${ }^{26}$

O Estado monárquico imperial aparecia como o elemento unificador das partes distintas e dispersas do mundo português, e o sentimento de pertencimento à nação lusa, então explicitamente evocado, exerceria também a função asseguradora da unidade do território português na América, até então reconhecido sob o "genérico nome de Brasil". ${ }^{27}$

Retornando à análise da Memória de Câmara, na primeira parte, intitulada "Estrutura física" da Comarca de Ilhéus, há informações sobre a situação geográfica, os limites, a extensão da superfície, a configuração do terreno, o ar em geral, os rios, as vilas e as matas, entre outras. Nessa parte do texto, a localização dos rios e das baías foi o objeto que mais recebeu atenção, revelando assim um naturalista pragmático em sua procura por boas enseadas e portos para a entrada e saída de embarcações. Certamente a facilitação do comércio constituía uma preocupação do autor, como ficou claro em sua argumentação sobre a importância da barra de Camamu:

Por meio desta excelente barra se pode fazer um comércio direto com o Reino, e exportar tudo quanto este vasto continente pode produzir, independentemente de qualquer outro porto marítimo do Brasil. ${ }^{28}$

\footnotetext{
${ }^{26}$ Apud Maria de Lourdes Viana Lyra, op. cit., p. 87.

${ }^{27}$ No momento da crise final do sistema colonial, não havia um território brasileiro unificado no plano político. Havia, na feliz expressão de Demétrio Magnoli, "blocos de colônias" vinculados diretamente à metrópole pela administração das capitanias hereditárias, configurando elementos de um todo que era o Império Português. Demétrio Magnoli, "O Estado em Busca do seu Território", in: István Jancsó (org.), Brasil: a formação do estado e da nação, São Paulo, Fapesp, Editora Hucitec, 2004, p. 294.

${ }^{28}$ Manuel Ferreira da Câmara, Ensaio de Descrição Física, e Econômica da Comarca dos Ilhéus na América (1789), op. cit, p. 260.
} 
Na segunda parte da Memória, intitulada "Do estado atual da sua agricultura, e do seu comércio", Câmara argumentou que os habitantes de Ilhéus só cultivavam e comercializavam a mandioca e o arroz, e não empreendiam novos ramos de lavoura. Para ele, era necessário diversificar a produção agrícola local com novos cultivos, como as uvas, o cacau, o tabaco, o açúcar, entre outros, e tentar aclimatar na região "uma grande parte dos frutos da Europa, que vulgarmente se encontram em todo o Brasil", como a maçã, o marmelo, o pêssego e as ameixas, além de outros. E, também "grande parte dos legumes e plantas" de que se alimentam os habitantes europeus.

A terceira parte do estudo foi dividida em três itens. No primeiro, o autor argumentou sobre a necessidade de uma "reforma da agricultura" na Comarca de Ilhéus. Apontou os gêneros agrícolas que eram cultivados na Comarca, como o cacau, e aqueles que deveriam ser transplantados, como a canela, o cravo do Maranhão, a salsaparrilha, a contra-erva, a ipecacuanha, o café, o açafrão, o anil, o tamarindo, o algodão e a cana-de-açúcar, entre outros, sempre mencionando a sua importância e utilização econômica.

A afirmação da agricultura como a principal fonte de riqueza é um tema bastante presente nos estudos dos naturalistas luso-americanos do período abordado aqui. Domingos Vandelli, por exemplo, colocava a agricultura entre suas primeiras preocupações. O professor italiano publicou diversas memórias na Academia Real das Ciências de Lisboa, tratando da agricultura e da sua importância para o desenvolvimento do Reino. No conjunto de publicações da Academia, a agricultura é um dos assuntos que mais aparecem. ${ }^{29}$

A agricultura, sem dúvida, dominava as atenções dos naturalistas da Academia. Contudo, devemos estar atentos para o fato de que essa preocupação prevalecente com a agricultura não significava uma adesão sistemática à fisiocracia. De acordo com Fernando Novaes, o pensamento fisiocrático era mobilizado para servir a uma política reformista. ${ }^{30}$ Embora a preocupação com a agricultura fosse preponderante nas memórias dos vários sócios, muitos deles tendiam para um ecletismo, caracterizando a postura metodológica dos ilustrados portugueses. ${ }^{31}$

\footnotetext{
${ }^{29}$ Oswaldo Munteal Filho, op. cit.

${ }^{30}$ Vera Ferlini argumentou que as proposições dos sócios da Academia referentes à agricultura não assumiam uma postura revolucionária, mas reformista. Os acadêmicos não questionavam em momento algum a estrutura agrária do antigo regime português, nem atacavam a propriedade e as relações de produção vinculadas estritamente aos privilégios estamentais do clero e da aristocracia. Vera Lúcia Amaral Ferlini, "A Questão Agrária no Pensamento Reformista Luso-Brasileiro do Século XVIII: Estrutura Fundiária, Legislação Territorial e Proposta de Mudanças", in Maria Fernanda Bicalho et al. (org.), Modos de governar. Idéias e práticas políticas no Império Português. Séculos XVI a XIX, São Paulo, Alameda, 2005, p. 299.

${ }^{31}$ Fernando A. Novais, op. cit.
} 
O segundo item da terceira parte da Memória teve como tema a importância das pescas que se realizavam na costa da Comarca de Ilhéus. Segundo Câmara, a pesca deveria ser vista como um ramo de riqueza e de comércio exterior, uma vez que poderia gerar "produtos úteis às artes, e aos usos econômicos", como a pesca das baleias e a extração do seu azeite. Contudo, o autor afirmou que a pesca das baleias em Ilhéus estava sujeita a infinitos erros, precisando urgentemente de uma "reforma", que tornaria tal atividade altamente lucrativa ao Estado.

O terceiro item teve como tema a "Cultura, conservação e corte das madeiras". Câmara discorreu sobre a importância das matas para Portugal e para o Brasil, sobretudo no que diz respeito "à construção, e à combustão diária". No entanto, os habitantes estavam destruindo tais produções vegetais, de tal forma que faltavam todas as "espécies de preciosas madeiras", e, com o tempo, este se tornaria um "gênero mui caro". O naturalista então apontou a necessidade de o Estado controlar a exploração irregular das matas por meio da nomeação de ministros que "vigiem, e regulem o corte das madeiras em geral e indistintamente" e obrigar os habitantes a se preocuparem com a reprodução de tais espécies vegetais.

A preocupação de Câmara com a conservação das matas reside no fato de essas produções vegetais serem fontes importantes de madeiras para a construção das casas, assim como para a construção de navios. Lembremos também que, sendo o autor um "metalurgista de profissão", tinha ele uma profunda consciência a respeito da exploração racional das árvores, pois estas eram fontes de abastecimento energético das siderúrgicas e dos engenhos, uma vez que o carvão, fonte de combustível com o advento da revolução industrial inglesa, não existia em quantidade suficiente em Portugal e no Brasil. A falta de lenhas, de madeiras e de carvão paralisaria a produção das ferrarias e com o aumento progressivo de mais fornos e forjas, como convém, nem estabelecerem-se para o futuro fábricas de aço, espingardas, cutelaria e outras oficinas úteis, de que muito precisam os meus Reinos [do Rei de Portugal]. ${ }^{32}$

Lembremos que a madeira era considerada, antes do surgimento da revolução industrial, a principal fonte de combustível. ${ }^{33} \mathrm{~A}$ descoberta do carvão mineral como elemento capaz de servir como combustível para a indústria si-

\footnotetext{
${ }^{32}$ Alex Gonçalves Varela, op. cit., p. 179.

${ }^{33}$ De acordo com John Perlin, os esteios de madeira suportavam os poços das minas para a extração do carvão mineral. Em seguida, o carvão era embarcado em carretas de madeira para as fábricas siderúrgicas, sobre trilhos de madeira ou em navios de madeira por canais cujas comportas também eram de madeira. Posteriormente, a madeira foi substituída por ferro. John Perlin, História das florestas: a importância da madeira no desenvolvimento da civilização, Rio de Janeiro, Imago, 1992.
} 
derúrgica na produção de ferro, sobretudo para o seu refino e fundição, pôs fim à "era da madeira" enquanto principal material de construção e combustível da civilização. O carvão passou a ser a principal fonte de energia industrial do século XIX, bem como um importante combustível doméstico. ${ }^{34}$

Daí a argumentação de Câmara em prol da conservação das matas e dos bosques. Portugal e a sua principal possessão colonial, o Brasil, não tinham depósitos de carvão mineral. Por sua vez, a diminuição de tais recursos naturais aumentaria a dependência de Portugal com relação à Inglaterra, sobretudo com os gastos relacionados à importação de carvão. A solução para tal questão era continuar a utilizar a madeira como fonte de combustível. Em função disso, a exploração irracional das matas e dos bosques deveria ser freada, e o Estado português passaria a ser o agente único e exclusivo de utilização e exploração racional dessas produções vegetais. Portanto, a conservação das produções vegetais está intimamente associada aos interesses pecuniários do Estado português, não tendo preocupação humanística alguma com o bem-estar e a qualidade de vida da população portuguesa. ${ }^{35}$

A segunda dissertação apresentada no ano de 1789, em agosto, intitulase Memória de Observações Físico-Econômicas Acerca da Extração do Ouro do Brasil.

Esse estudo de Câmara está inserido em um vasto acervo de memórias, artigos e discursos elaborados entre o final do século XVIII e o início do XIX em torno da recuperação do setor de produção mineral no Brasil, nomeadamente a de ouro. Dentre esses escritos, destacamos dois exemplos: o Discurso Sobre o Estado Atual das Minas do Brasil, do bispo José Joaquim da Cunha Azeredo Coutinho, publicado em 1804 pela Imprensa Régia, em Lisboa, que considerava a mineração a razão da decadência de Portugal; e o Discurso Sobre a Verdadeira Influência das Minas dos Metais Preciosos na Indústria das Nações que as Possuem, e Especialmente da Portuguesa, escrito por D. Rodrigo de Sousa Coutinho, publicado pela Academia Real das Ciências de Lisboa, tomo I, das Memórias Econômicas (1789-1815), que afirmava a importância da mineração enquanto atividade geradora de riquezas para a nação portuguesa.

\footnotetext{
${ }^{34}$ Eric Hobsbawm, A era das revoluçoes, Rio de Janeiro, Paz e Terra, 1987.

${ }^{35}$ Sobre o conservacionismo nas memórias científicas dos ilustrados luso-americanos setecentistas, ver: José Augusto Pádua, A degradação do berço esplêndido: pensamento político e crítica ambiental no Brasil escravista, 1786-1888, Rio de Janeiro, Jorge Zahar, 2002.
} 
No âmbito desse debate dos que se colocavam a favor ou contra a mineração, ${ }^{36}$ o texto de Câmara se destaca por se alinhar aos defensores da recuperação da mineração para o desenvolvimento econômico da nação portuguesa, como D. Rodrigo, José Bonifácio e José Vieira Couto. A posição defendida pelo naturalista transparece na seguinte passagem da Memória:

Como a nação que tem indústria, agricultura e comércio e minas é mais rica que outra, que tendo indústria, agricultura e comércio não tem minas, claro fica que só por esta razão devem as minas ser fomentadas. De mais como nenhuma nação, por mais ativa e industriosa que seja, pode bastar a si própria, por não poder ter todos os gêneros de primeira necessidade, luxo ou capricho, porque a natureza não dá a todas tudo (...) temos por consequência, que o remédio mais pronto é o de animar as minas, e tirar delas todo o partido com que possa pagar o que recebe de fora, e pôr-se ele mesmo no estado de independência. ${ }^{37}$

A primeira parte da Memória divide-se em dois capítulos. No primeiro, o naturalista apresenta uma pequena exposição da história dos descobrimentos das minas na Capitania de Minas Gerais. Destaca a falta "aos paulistas e mineiros" dos principais conhecimentos sobre mineralogia, geometria subterrânea e docimástica, fato que possibilitava apenas que entrassem em contato com o ouro presente à "flor da pele". Dessa forma, não poderiam extrair ouro das pedras das montanhas - segundo o naturalista, ali residia "a origem da extração do ouro mais difícil” -, pois seriam necessários importantes conhecimentos científicos para realizar a atividade mineradora. De acordo com o espírito do Século das Luzes, Câmara expressou sua confiança na instrução dos mineiros como uma das mais importantes atitudes a serem tomadas para a superação da crise pela qual passava o setor. Tornava-se necessário criar escolas de mineralogia que ensinassem os princípios fundamentais da arte mineira, deixando transparecer a fé na educação e na ciência.

No segundo capítulo, o autor trata das matrizes em que se encontrava o ouro, afirmando que se poderia achar o metal em "cascalhos ou em vieiros, ou matrizes quartzosas, vulgarmente minas de pedra”. Essa preocupação do

\footnotetext{
${ }^{36}$ Sobre o debate entre aqueles que se colocavam a favor ou contra a recuperação da mineração para o desenvolvimento econômico da nação portuguesa, ver a tese de doutorado de: Clarete Paranhos da Silva, Garimpando memórias: as ciências mineralógicas e geológicas no Brasil na transição do século XVIII para o XIX, Tese (Doutorado em Ciências da Terra), Universidade Estadual de Campinas, Campinas, 2004.

${ }^{37}$ Manuel Ferreira da Câmara, "Memória de Observações Físico-Econômicas Acerca da Extração do Ouro do Brasil (1789)", in Marcos Carneiro de Mendonça. O intendente Câmara, op. cit., p. 502.
} 
naturalista em descrever os locais da ocorrência dos metais, assim como a sua matriz, era uma prática que estava de acordo com as modificações pelas quais passava a Mineralogia no final do século XVIII, quando já não importava somente coletar e identificar os materiais minerais, mas verificar como se dava sua distribuição no espaço. ${ }^{38}$ A Mineralogia ia deixando de ser uma ciência essencialmente de laboratório, que objetivava tão-somente registrar e sistematizar objetos minerais, e passava a ter uma dimensão geográfica. Em decorrência disso, tornou-se consenso a idéia de que rochas e minerais colecionados em gabinetes podiam dar muito prazer, mas não trariam nenhuma luz à razão se não fossem observados no local de sua ocorrência. ${ }^{39}$ Portanto, Câmara seguia os caminhos próprios de sua ciência, no estágio em que se encontrava naquele período. Estava atento ao que ocorria em relação à ciência que praticava, como bem mostram os seus textos. ${ }^{40}$

Câmara alertou para os erros que os mineiros estavam cometendo na extração do ouro das minas de pedra, uma vez que naquelas o metal se encontrava "intimamente combinado, e dividido em massas que chegam a nadar ao cume da água". Segundo o autor, o método utilizado pelos mineiros estava trazendo grandes prejuízos ao Estado português, que chegava a perder cerca de "66 milhões". E, de acordo com Câmara, nos mesmos tipos de minas encontradas em Schemnitz e Kremnitz, ${ }^{41}$ a "Coroa da Alemanha” conseguiu obter lucros consideráveis a partir da atividade de mineração.

No terceiro capítulo, o autor apresenta algumas críticas acerca das práticas de mineração e propõe a utilização, em lavra subterrânea, de um ventilador de invenção recente; de um engenho de pilões, por ele aperfeiçoado, antes de o ouro entrar nos moinhos; e ainda de moinhos que favoreciam a cominuição da pedra e amalgamação do ouro. Quanto à separação do metal, fez referência a vasos e fornos em que a destilação do mercúrio ocorreria com vantagem e

\footnotetext{
${ }^{38}$ Martin Rudwick, "Minerals, strata and fossils", in N. Jardine et al. (org.), Cultures of natural history, Cambridge, Cambridge University Press, 1997.

${ }^{39}$ E. P. Hamm, "Knowledge From Underground: Leibniz Mines the Enlightenment", Earth Sciences History, New York, v. 16, n. 2, 1997.

${ }^{40}$ Lorelai Brilhante Kury, "Homens de Ciência no Brasil: Impérios Coloniais e Circulação de Informações (1780-1810)", História, Ciências, Saúde - Manguinhos, Rio de Janeiro, vol. 11, suplemento 1, 2004, p. 113; Ana Maria Cardoso de Matos, Ciência, tecnologia e desenvolvimento industrial no Portugal oitocentista. O caso dos lanifícios do Alentejo, Lisboa, Editorial Estampa, 1998.

${ }^{41}$ Cidades que pertencem ao atual território da Hungria, importantes centros mineiros desde os tempos dos romanos.
} 
ainda a um método de recuperação deste. E propôs, também, a aplicação do método de fusão à extração do ouro combinado.

No quarto capítulo, Câmara inicia criticando as casas de fundição anexas às minas da América Portuguesa, cuja finalidade era a fusão do ouro, a determinação dos quilates e a percepção do quinto do ouro extraído, destinado à Coroa. Tais funções eram preenchidas de forma deficiente, o que conduzia ao contrabando do ouro e a prejuízos para o Estado português.

A seguir, o autor passa a discorrer sobre a jurisprudência das minas. Critica os princípios, vigentes no Reino, de que interessava mais ao Estado "a divisão do que a terra contém no seu interior, que a extração exclusiva". Tal princípio era exatamente o oposto do que se passava nos Estados "mais civilizados", em que aos soberanos pertencia o direito de extrair as minas, cunhar seu produto e torná-lo próprio à circulação do Estado. Nota-se que Câmara defendia a presença firme do Estado no controle da atividade mineradora e de uma legislação que permitisse racionalizar a produção mineral.

Em conseqüência desse fato, Câmara propôs uma série de medidas que visavam fomentar as minas, como a redução dos impostos sobre os artigos que mais diretamente serviam à extração (ferro, aço, panos etc.) e sobre os direitos de entrada no Brasil dos escravos destinados às regiões mineiras; a boa regulação e direção das Casas de Fundição; a participação dos descobridores das minas nos lucros das minas; o estabelecimento de companhias de mineiros destinadas à recuperação das minas; e, por fim, o estabelecimento de Casas de conselhos nas províncias mineiras com as funções de: preparar técnicos de minas (geômetras, fundidores e outros homens hábeis) em colégios situados junto às minas, onde se promovesse o ensino da mineração; verificar os métodos de extração e prover o aconselhamento técnico aos mineiros que o solicitassem; fazer os ensaios e a fusão do ouro; deliberar sobre a conveniência ou não de fazer a extração de qualquer mina.

De acordo com Câmara, as propostas aqui mencionadas deveriam ser seguidas, uma vez que a legislação sobre as minas da América Portuguesa não facilitava a sua extração. A inspiração para um novo regimento deveria provir dos "estatutos e ordenações das minas mais célebres da Europa", como as da Saxônia, de Eisleben, de Mansfield e do Hart, entre outras, onde por "sábios regulamentos se tem chegado ao cume da felicidade".

Finalmente, Câmara sugere o estabelecimento de colégios nos países mineiros com a função de ensinar tudo o que fosse "necessário à extração dos 
metais, uma vez que a principal causa, que pode animar a extração das minas, em um país favorecido pela natureza, é encaminhar o gênio da nação ao gosto, e prazer da extração delas". ${ }^{42}$ Contudo, defende o autor que a melhor forma para se adquirirem os conhecimentos mineiros seria a experiência prática na própria região das minas.

No ano de 1790, Câmara apresentou a Memória intitulada Observações Feitas Por Ordem da Real Academia de Lisboa Acerca do Carvão de Pedra, Que se Encontra na Freguesia da Carvoeira. Nesse estudo, narra as diligências realizadas com um pedaço de "carvão de pedra piritoso", encontrado no sítio da Freguesia da Carvoeira e levado pelo seu proprietário para ser examinado na Academia. A instituição nomeou o naturalista para examinar o mencionado material mineral e saber se dele poder-se-ia extrair enxofre.

Após realizar as experiências, Câmara constatou que o carvão do sítio da Carvoeira, ainda que não tivesse as mesmas qualidades do inglês, seria capaz de produzir "os efeitos de uma boa substância inflamável, e que a sua aplicação é mais geral, que a dos carvões mais carregados de partes betuminosas". ${ }^{43}$ Dessa forma, justificava a utilização econômica do recurso natural para ser empregado como fonte de energia nos fornos e forjas das fundições de ferro e chumbo portuguesas, o que diminuiria a dependência em relação ao carvão da Inglaterra.

Câmara foi convidado pelo mesmo proprietário do sítio da Carvoeira para analisar outros bancos de carvão em sítios mais altos, como na fazenda "o Casalinho". Aceitou prontamente, uma vez que para ele "era grande desejo que tinha de examinar o interior daqueles montes terciários, e ver se em maior profundidade encontrava banco [de carvão] mais rico". ${ }^{44}$

Na passagem mencionada, Câmara utilizou o termo "montes terciários". Era freqüente entre os estudiosos da terra do período aqui estudado fazer uso das expressões primeira ordem, segunda ordem e terceira ordem. Estes adjetivos estavam de acordo com a nomenclatura do período e correspondiam aos termos "montanhas primárias", "montanhas secundárias" e "montanhas terciárias”, respectivamente, dizendo respeito à idade relativa das rochas,

\footnotetext{
${ }^{42}$ Manuel Ferreira da Câmara, "Memória de Observações Físico-Econômicas Acerca da Extração do Ouro do Brasil”, op. cit., p. 522.

${ }^{43}$ Manuel Ferreira da Câmara, "Observações Feitas Por Ordem da Real Academia de Lisboa Acerca do Carvão de Pedra, que se Encontra na Freguesia da Carvoeira (1790)", in Marcos Carneiro de Mendonça, O intendente Câmara, op. cit., p. 210.

${ }^{44}$ Ibidem, p. 207.
} 
sendo as primárias as mais velhas e as terciárias as mais novas. ${ }^{45} \mathrm{O}$ conhecimento da ordem das montanhas da região e da disposição de seus veios seria útil ao desenvolvimento da arte de minerar, na medida em que isso resultaria na aplicação de técnicas mais adequadas à mineração dos montes, uma vez que, por possuírem veios que entravam para o centro da terra, sua mineração teria de ser necessariamente diferente da dos rios, onde a ocorrência do ouro era superficial.

A leitura de diversos trechos da memória nos permite observar uma linguagem que se caracteriza como o conjunto das práticas científicas mineralógicas do século XVIII, segundo a historiadora das geociências Rachel Laudan. ${ }^{46}$ Havia um consenso, entre os estudiosos, de que a crosta terrestre era formada por terras, metais, sais e substâncias betuminosas. Essas classes de minerais poderiam ser diferenciadas umas das outras por suas reações ao fogo ou à água, ou, então, pelo fato de esses minerais terem sido fluidos, tendo-se solidificado por retirada de água ou de calor. Esse conjunto de questões foi o que Laudan chamou de conjunto de práticas científicas da mineralogia no século XVIII. Câmara empregou termos como pedras, terras, minerais, sais, enxofres e metais, seguindo assim esse conjunto de práticas.

A dissertação possibilita observar os sistemas de classificação dos minerais que Câmara utilizava. Ao identificar e descrever o carvão presente no sítio da Carvoeira, observa-se que Câmara fez uso dos sistemas de classificação de minerais de Johan Gottschalk Wallerius e de Carl von Linné (Lineu). O botânico Lineu classificou os minerais seguindo o modelo que ele utilizava para classificar as plantas e enfatizando os seus caracteres externos. Rachel Laudan verificou que esse modelo foi bastante empregado nas classificações de minerais nos anos que se seguiram ao seu surgimento, em 1735, mas começou a ser criticado pela maioria dos mineralogistas à medida que estes iam percebendo que o "reino mineral e o reino vegetal diferiam tão radicalmente que os conceitos e métodos que funcionavam para o último não poderiam ser aplicados ao primeiro". ${ }^{47}$

O sistema de classificação de Wallerius baseava-se em modelo químico e dava ênfase aos caracteres internos dos minerais. Esse estudioso distinguia os caracteres internos e os externos dos minerais. Os externos que permitiriam

\footnotetext{
${ }^{45}$ Martin Rudwick, op. cit.

${ }^{46}$ Rachel Laudan, From mineralogy to geology: the foundations of a science, 1650-1830, Chicago, The University of Chicago Press, 1987.

${ }^{47}$ Rachel Laudan, op. cit.
} 
a classificação eram a cor, o gosto, a forma, o cheiro, os usos e a ocorrência. Quando não fosse possível a classificação por meio desses caracteres externos, processavam-se análises químicas. ${ }^{48}$

O uso de sistemas de classificação tão diversos remete-nos à formação de Câmara na Universidade de Coimbra, na qual prevalecia um enfoque eclético e pragmático. Naquele espaço institucional, o naturalista foi aluno do paduano Domenico Vandelli, primeiro lente de química da Universidade de Coimbra e também professor de História Natural, seguidor do método de Lineu nas cadeiras que lecionava.

Não somente Câmara, mas toda uma geração de naturalistas formados por Vandelli, entre eles José Bonifácio de Andrada e Silva, José Vieira Couto, ${ }^{49}$ Martim Francisco Ribeiro de Andrade, ${ }^{50}$ entre outros, estudaram segundo as doutrinas de Lineu, adotadas nas aulas do professor coimbrão.

\section{A viagem científica pela Europa Central e Setentrional}

No espaço da Academia Real das Ciências de Lisboa, Câmara e José Bonifácio despertaram as atenções de alguns membros, entre os quais o duque de Lafões. Como resultado da admiração deste último, ganharam uma bolsa de estudos do governo português para fazer uma viagem científica pela Europa, juntamente com Joaquim Pedro Fragoso. Para a realização desse empreendimento, o ministro Luiz Pinto de Souza baixou uma minuciosa Instrução para a realização da viagem de aperfeiçoamento técnico através da Europa (31.5.1790). Nela determinou-se que Manuel Ferreira da Câmara seria o "chefe de Brigada" e responsável pela "decisão do tempo dos estudos e das viagens, do destino de cada um dos sócios, e dos sítios onde deviam empregar-se". ${ }^{51}$

O recebimento da bolsa de estudos para a realização da viagem oferecida pelo governo português deixou transparecer a inserção de José Bonifácio

\footnotetext{
$\overline{{ }^{48} \text { Martin Guntau, "The natural history of the Earth", in N. Jardine et al. (orgs.), Cultures of }}$ natural history, Cambridge, Cambridge University Press, 1997.

${ }^{49}$ Clarete Paranhos da Silva, O desvendar do grande livro da natureza. Um estudo da obra do mineralogista José Vieira Couto, 1798-1805, São Paulo, Annablume, Fapesp; Campinas, Unicamp, 2002.

${ }^{50}$ Alex Gonçalves Varela, Atividades científicas na "bela e bárbara" Capitania de São Paulo (1796-1823), Tese (Doutorado em Ciências da Terra), Universidade Estadual de Campinas, Campinas, 2005.

${ }^{51}$ Edgard de Cerqueira Falcão (org.), "Obras científicas, políticas e sociais de José Bonifácio de Andrada e Silva”, vol. III, Santos, Revista dos Tribunais, 1963, p. 169.
} 
e Ferreira da Câmara na Lógica do Prestígio, ${ }^{52}$ na medida em que viviam sob a proteção do Estado (por meio de cargos, pensões, mesadas etc.). Vivendo literalmente às custas da Coroa portuguesa, passavam a ter uma posição privilegiada em sua sociedade. Privilegiada porque significava a proximidade com a Coroa, a participação em sua vida e o recebimento de pensões. Privilegiada porque dependente. Portanto, o trabalho dos dois naturalistas não pode ser dissociado do seu papel enquanto cortesões, uma vez que a vida na Corte moldaria a sua vida quotidiana e a sua atividade científica. E, na Corte, espaço social em que as regras eram determinadas pelo príncipe, a história natural desfrutava de amplo reconhecimento, uma vez que teria um papel central nos projetos econômicos, políticos e culturais da segunda metade do século XVIII no Império Português. ${ }^{53}$

Cabe registrar que Manuel Ferreira da Câmara, personagem que vivia na sociedade do Ancien Régime, teve a sua carreira enquanto naturalista caracterizada por encerrar-se completamente na fidelidade a uma espécie de dupla identidade, como assim constatou Vicenzo Ferrone ${ }^{54}$ em sua análise sobre o estudioso das ciências do século XVIII.

Primeiro, observa-se a sua adesão ao modelo do homem de ciência organicamente ligado ao Estado, que aceitava inteiramente a lógica e os valores de uma sociedade hierarquizada, estabelecida, organizada por ordens, classes e corpos diferenciados pelas dignidades, honras, onipresença do privilégio e categorias. O Estado atribuía ao estudioso das ciências honras e privilégios, conforme o costume e a lógica do Ancien Régime, privilégios que iam desde uma isenção parcial dos rendimentos à dispensa do serviço militar, à enorme possibilidade de ser levado à presença do rei, ao recebimento de bolsas de estudo, à participação no cerimonial da Corte e nas manifestações públicas. $\mathrm{O}$ compromisso com o monarca e com o sistema de organização da vida intelectual assente no patronage permitia, aliás, desenvolver a fundo as potencialidades do método científico e aumentar o número dos protagonistas em virtude dos financiamentos, das pensões, dos privilégios distribuídos pelo soberano. $\mathrm{O}$ homem de ciência do século XVIII, no contexto do antigo regime, era basicamente um funcionário do Estado, cujas atividades eram financiadas pelos monarcas, revelando assim o pacto tácito com o poder.

\footnotetext{
${ }^{52}$ Nobert Elias, A sociedade de Corte, Lisboa, Editorial Estampa, 1995.

${ }^{53}$ Mario Biagioli, Galileu, cortesão. A prática da ciência na cultura do Absolutismo, Porto, Porto Editora, 2006.

${ }^{54}$ Vicenzo Ferrone, "O homem de ciência”, in Michel Vovelle (org.), O homem do Iluminismo, Lisboa, Editorial Presença, 1997.
} 
Observa-se, entretanto, na prática científica do naturalista a adesão e difusão do enciclopedismo, a ideologia científica do progresso, o utilitarismo e o pragmatismo, assim como a vontade e o desejo de classificar os elementos do mundo natural, traços que caracterizam o moderno pensamento científico. Ademais, registremos o fato de ser membro da "República das Letras", com os seus valores cosmopolitas, uma vez que participava ativamente de inúmeras sociedades científicas e publicava os trabalhos de suas pesquisas que seguiam o método moderno da observação e da experimentação.

$\mathrm{Na}$ Instrução estavam listados determinados locais pelos quais os filósofos deveriam passar. O percurso, longe de ser delineado arbitrariamente, era estipulado pelo poder administrativo. Em segundo lugar, os participantes contariam com uma ampla rede de diplomatas em todos os locais que visitassem, facilitando a entrada e a permanência nos países determinados pelo poder régio.

Primeiramente deveriam ir à França, país expoente da Ilustração européia e onde ocorreu a chamada "revolução química", liderada por Antoine Laurent Lavoisier, assim como importante centro em que se desenvolveu a Escola de Mineralogia Cristalográfica, que teve como expoentes Romé de L'Isle e o abade René-Just Haüy.

Em Paris, José Bonifácio e Câmara fizeram o curso de Fourcroy. Ao freqüentar as aulas desse importante químico francês, os estudiosos entraram em contato com as principais idéias da "revolução química", uma vez que Fourcroy havia colaborado para a formulação da "nova" nomenclatura química, baseada na teoria da oxidação e da combustão, e que negava a existência do flogisto. Aceitar a nova nomenclatura significava, assim, aderir às novas idéias. ${ }^{55}$

Por sua vez, o curso de mineralogia programado para ser lecionado pelo professor Le Sage não foi realizado sob a responsabilidade deste, mas do professor Guillot Duhamel, na Escola de Minas de Paris. Se tivessem feito o curso de Le Sage, José Bonifácio e Câmara teriam estudado a mineralogia docimástica, área de especialização do estudioso francês. O curso que Duhamel oferecia na Escola de Minas estava relacionado "à arte do minerador, à arte do metalurgista, à geometria elementar subterrânea, teórica e prática, ou ao tratado dos filões ou veios mineralógicos e sua disposição pelo seio da terra". ${ }^{56}$

Após o período na França, os filósofos passaram pela Holanda e, a seguir, dirigiram-se, seguindo a Instrução, para Freiberg, na Saxônia, centro

${ }_{55}$ Bernadette Bensaude-Vincent; Isabelle Stengers, História da química, Lisboa, Instituto Piaget, 1996.

${ }^{56}$ Gabriele Arlet, D’héphiasitos à Sphia Antipolis-mineurs et forgérons, vol. I, Paris, St. Etienne, Gédim, 1991, p. 97. 
mais avançado em mineração e estudos correlatos da Europa, além de sediar a primeira academia de minas do mundo, a Bergakademie Freiberg. Nesse local, José Bonifácio e Câmara assistiram ao curso de orictognosia e geognosia administrados pelo professor Abraham Gottlob Werner, de quem se tornariam discípulos.

A geognosia (literalmente, "conhecimento da terra") era o campo da mineralogia relativo à classificação das massas das rochas e suas relações espaciais. Os geognostas, como eles próprios se chamavam, tentavam definir e descrever as formações que seriam reconhecidas para além de uma simples região, alcançando escalas globais. A tarefa de reconhecer formações em diferentes locais e, assim, tornar a classificação tão aplicável quanto fosse possível foi tentada empiricamente por diferentes critérios. ${ }^{57}$

Para Werner, a geognosia era uma subdivisão da mineralogia. Ela distinguia-se da mineralogia geográfica, que estudava a distribuição das rochas e dos minerais pela superfície, e da orictognosia, a qual estudava as substâncias "fósseis" do subsolo.

Em Freiberg, Câmara publicou dois artigos no Bergmanniches Journal, sobre as pedras obsidianas, deixando transparecer claramente os ensinamentos do mestre saxão, sobretudo a adesão à teoria netunista. ${ }^{58}$ Werner, tendo como base a tradição química presente na mineralogia, admitia que praticamente todas as rochas se originaram por precipitação e cristalização a partir de um oceano primordial, cuja denominação mudaria ao longo do próprio processo, daí derivando a denominação Netunismo. Utilizando também o conceito de superposição formulado por Nicolau Steno (1638-1686) mais de um século antes, Werner classificou os terrenos em razão de sua ordem de cristalização/ formação, dos mais antigos ("primitivos", nos quais incluía o granito) aos mais novos ("recentes", nos quais incluía as rochas vulcânicas).

Nos artigos de Câmara sobre a obsidiana termos e idéias netunistas estão bastante presentes. Ao analisar a obsidiana sob o tubo de sopro, ${ }^{59}$ Câmara

\footnotetext{
${ }^{57}$ Martin Rudwick, op. cit.

${ }^{58}$ Os netunistas eram seguidores do modelo do mineralogista saxão Werner, o qual atribuía à água o papel preponderante na formação da crosta terrestre, em contraposição ao escocês James Hutton, defensor da teoria denominada plutonista, que enfatizava a ação interna como a responsável pela formação das rochas. Sobre a controvérsia entre netunistas e plutonistas, ver: Anthony Hallam, Grandes controvérsias geológicas, Barcelona, Labor, 1982.

${ }^{59}$ Câmara, Manuel Ferreira da. "Sobre o comportamento da obsidiana sob o tubo de sopro, pelo Sr. Da Câmara" (traduzido do francês). Freiberg, Bergmanniches Journal, v. 6, n. 1, p. 280-285, 1794. (Tradução para o português de Miriam Junghans)
} 
finalizou afirmando que estava "inclinado a acreditar que todos aqueles que consideram a obsidiana um produto vulcânico nunca a manipularam no fogo". De acordo com o estudioso, a obsidiana exposta isoladamente à chama do fogo do tubo de sopro não consegue "externar a sua força de fusão, perde a sua cor, origina um vidro vesiculoso e não se funde facilmente com álcalis". A essas razões apresentadas, Câmara acrescentou as "geognósticas, que devemos ao Sr. Werner" para confirmar que as obsdianas têm uma origem sedimentar. Por sua vez, num segundo artigo, ${ }^{60}$ ao analisar a obsidiana da ilha de Kandia, considerou-a um "produto das águas", e não um produto ígneo.

Após a estada em Freiberg, onde obtiveram conhecimentos que os prepararam como mineiros, Câmara e Bonifácio visitaram diversas minas na Áustria, no Tirol, na Caríntia, na Estíria e no norte da Itália. Após estarem juntos em todos os locais até agora mencionados, em janeiro de 1796 partiram para rumos diferentes. Câmara foi visitar as minas da Transilvânia e do Banat. ${ }^{61}$ Por sua vez, Bonifácio foi em direção à Alta Hungria. Depois, individualmente, visitaram regiões mineiras da Suécia, Noruega e Dinamarca. Câmara ainda esteve na Inglaterra, visitando as minas de carvão e as de extração de metais, enquanto Bonifácio não esteve por lá. Pelas informações que obtivemos, os estudiosos não visitaram as minas de Ekatharinemburgo, na Rússia, e também não foram à Espanha, conhecer as minas de Almadén.

Na região da Transilvânia, importante centro europeu de tradição de exploração mineira de metais nobres, Câmara elaborou um texto intitulado Nota Sobre a Extração das Minas do Principado da Transilvânia escrita em Zalathna aos cinco dias do mês de março de $1796 .{ }^{62}$

\footnotetext{
${ }^{60}$ Câmara, Manuel Ferreira da. "Carta do Sr. da Camera de Bethencourt ao Sr. Hawkins, acerca de alguns experimentos com obsidiana" (traduzido do francês). Freiberg, Bergmanniches Journal, v. 6, n. 2, p. 239-249, 1794. (Tradução para o português de Miriam Junghans)

${ }^{61}$ Região geográfica e histórica da Europa Central, atualmente dividida entre três países: na Romênia (os condados de Timis, Caras-Severin, Arad e Mehedinti), na Sérvia (localizado em sua maior parte na Voivodina) e uma pequena parte na Hungria (Condado de Csongrád).

${ }^{62}$ Região da Europa Central que constitui a atual zona centro-ocidental da Romênia. De acordo com Manuel Serrano Pinto, as razões que fizeram Câmara viajar para Zalathna e visitar a Transilvânia, passando lá o inverno de 1795-1796, foram: o excelente conceito das técnicas de fundição lá praticadas; a administração das atividades de mineração deveriam ser estudadas e comparadas com aquelas feitas no Brasil; e a administração geral da Transilvânia era centrada em Zalathna. Ainda seguindo o mesmo autor, no momento da visita de Câmara, o Soberano Habsburgo era Leopoldo II. A Transilvânia estava sob a dominação austríaca desde a ocupação feita por Leopoldo I em 1691. Manuel Serrano Pinto, "A Memoir Written in 1796 By Manoel Ferreira da Camara About Mining in Transylvania", in INHIGEO Meeting. Geological Resources and History. June 24th-July 1st/2001. Proceedings of the 26 th INHIGEO Symposium, Aveiro, Universidade de Aveiro/Centro de Estudos de História e Filosofia da Ciência e da Técnica, 2003, p. 363-372.
} 
A primeira parte do estudo versa sobre a legislação mineira e a administração das minas nos Estados Austríacos, que tinha como base a alemã, dando Câmara relevância aos seguintes pontos: o direito de extrair minas pertence à competência do Soberano; o Imperador poderia conceder o direito a qualquer um para explorar as minas desde que se comprometesse a seguir determinadas regras; a sua obrigação seria ajudar e socorrer as companhias mineiras; cada região mineira deveria ser administrada por um Conselho comandado pelo Soberano; a administração dos bosques estaria unida ao conselho das minas; os corpos de minas seriam independentes de qualquer jurisdição civil ou política; e a existência de um Conselho de Finanças que teria a seu cargo a administração e inspeção das minas, e cujos conselheiros eram instruídos na arte das minas e na economia montanhística. De acordo com o estudioso, esses foram "os fundamentos sobre que se fundaram as administrações mineiras, que me são conhecidas; foram estes os meios que tenho visto fazer uso por toda a parte para as minas, regular, e simplificar a extração das minas". ${ }^{63}$

A seguir, Câmara passou a informar detalhadamente as "diferentes partes da administração montanhística da Transilvânia”, mencionando os diversos metais extraídos, sobretudo o ouro, e a forma como o Soberano considerava a importância de cada um em particular. Logo depois, forneceu detalhes sobre os corpos institucionais da administração das minas nos Estados austríacos e na Transilvânia em particular.

Em diversos momentos do estudo, Câmara fez referências à mineração na América Portuguesa e em Portugal para servir de sugestões naquilo que deveria ser feito em termos de administração. O sistema alemão é que deveria ser seguido, como ocorrera na Transilvânia e em outros Estados austríacos, com o objetivo de modernizar, regularizar e simplificar a indústria das minas. Também fez diversas sugestões técnicas, apontou a necessidade de se mudar a legislação das minas em Portugal e aconselhou o governo português a tomar medidas administrativas similares às da Transilvânia em relação ao ouro em pó e ao ouro nativo.

A viagem de formação teórica e prática no campo da metalurgia e da mineração por diversos países da Europa Central e Setentrional fazia parte

\footnotetext{
${ }^{63}$ Manuel Ferreira da Câmara, "Nota Sobre a Extração das Minas do Principado da Transilvânia Escrita em Zalathna aos 5 de março de 1796", Loc.: Arquivo Nacional da Torre do Tombo, Núcleo do Ministério dos Negócios Estrangeiros, Caixa 526, folhas 4-5.
} 
da política portuguesa que visava arregimentar os estudiosos portugueses, nascidos ou não na metrópole, com o intuito de ajudar a promover a regeneração do Império. ${ }^{64}$ Não foi por acaso que a maioria desses ilustrados coloniais, entre os quais os dois mencionados naturalistas, pertenciam ao grupo de D. Rodrigo de Sousa Coutinho, ministro de D. Maria I, que defendia a necessidade de proceder a reformas profundas para conservar a integridade do Império português.

Nessa viagem, eles foram enviados para os principais distritos mineiros europeus, bem como para importantes centros técnico-científicos de grande destaque à época, como Freiberg, França e Saxônia, entre outros. O intuito dessa viagem foi o de observar o estado das ciências nesses países e de se aperfeiçoar, para assim poderem levar para Portugal os ares da modernidade. Essa prática de adesão às ciências modernas era buscada em diferentes lugares, selecionando os conhecimentos que mais lhes interessavam, uma vez que os centros científicos nem sempre eram os mesmos. A viagem, portanto, deixava transparecer o caráter exterior e eclético da Ilustração portuguesa.

A dimensão política vinha acoplada à dimensão científica. A viagem fazia parte do processo de modernização do Estado português no período do governo de D. Maria I. O Estado português buscou, na época, incentivar a formação de funcionários especializados com o intuito de ocupar cargos públicos estratégicos, sobretudo no campo da administração das minas. Após a realização dessa viagem, José Bonifácio e Manuel Ferreira da Câmara viriam a ocupar importantes funções no campo da mineração em Portugal e na Colônia, destacando-se ambos na administração conjunta das minas, matas e bosques. Os dois naturalistas aplicaram o seu saber científico a serviço da nação portuguesa, com o intuito de contribuir para as reformas que visavam

\footnotetext{
${ }_{64}$ Todo um conjunto de análises historiográficas tem mostrado como os ilustrados, tanto do Reino, como da Colônia, e aí inseridos Bonifácio e Câmara, elaboraram inúmeras propostas de modernização para o Estado lusitano, deixando assim transparecer o interesse pela manutenção da união entre Brasil e Portugal. Ver: Ana Cristina Araújo, "Um Império, um Reino e uma Monarquia na América: As Vésperas da Independência do Brasil”, in: István Jancsó (org.), Independência: história e historiografia, São Paulo, Fapesp; Editora Hucitec, 2005; Maria de Lourdes Viana Lyra, A utopia do poderoso império: Portugale Brasil-Bastidores da política, 1798-1822, Rio de Janeiro, Sette Letras, 1994; Maria Odila da Silva Dias, "A Interiorização da Metrópole", in Carlos Guilherme Mota (org.), 1822 - Dimensões, São Paulo, Perspectiva, 1972; Idem, "Aspectos da Ilustração no Brasil", Revista do Instituto Histórico e Geográfico Brasileiro, Rio de Janeiro, v. 278, janeiro-março de 1968, p. 105-170.
} 
regenerar o Império lusitano. Acima de tudo, eles eram portugueses, fiéis vassalos da Monarquia dos Braganças, comungando uma "identidade política coletiva" que remetia ao Estado português. ${ }^{65}$

Para Câmara e José Bonifácio, a viagem foi imprescindível para a especialização de suas respectivas trajetórias como naturalistas. Os dois tornaram-se, como eles próprios afirmavam, "metalurgistas de profissão".

Ao retornar a Portugal, Câmara e Bonifácio foram arregimentados por D. Rodrigo para assumir postos importantes no âmbito da administração central do Império Português, para a aplicação firme e eficiente da sua política reformista. Bonifácio foi nomeado Intendente Geral das Minas e Metais do Reino, órgão estatal que seria responsável pela política de pesquisa e exploração dos recursos minerais em Portugal. Por sua vez, Manuel Ferreira da Câmara seria enviado para a América Portuguesa, mais precisamente para a região de Minas Gerais, com o propósito de desempenhar a função de Intendente Geral das Minas na Capitania de Minas Gerais e Serro do Frio, região de exploração de diamantes e onde as relações de poder e sociais eram extremamente conflituosas. ${ }^{66}$

\section{Conclusão}

A análise da trajetória do processo de formação, especialização e profissionalização do naturalista Manuel Ferreira da Câmara revela a riqueza do pensamento ilustrado luso-americano. Formado em Filosofia, com ênfase nas ciências naturais, e especialização nas "artes mineiras e metalúrgicas", foi membro ativo do centro de irradiação das "luzes" em Portugal, a Academia Real das Ciências de Lisboa. Nesse espaço, apresentou diversas memórias científicas que revelam a atualização do seu pensamento científico. As carac-

\footnotetext{
${ }^{65}$ Como argumentaram István Jancsó \& João Pimenta, "nada de brasileiros, nenhuma identidade política ultrapassando o regional". Na verdade, isso não é de surpreender. A força coesiva do conjunto luso-americano era indiscutivelmente a Metrópole, e o continente do Brasil representava, para os colonos, pouco mais que uma abstração, enquanto para a Metrópole se tratava de algo muito concreto, a unidade cujo manejo impunha esta percepção. Por isso é correto afirmar que a "apreensão de conjunto das partes a que 'genericamente' se chamou de Brasil" estava no "interior da burocracia estatal portuguesa”. István Jancsó; João Paulo Garrido Pimenta, "Peças de um Mosaico (apontamentos para o estudo da emergência da identidade nacional brasileira)", in Carlos Guilherme Mota (org.), Viagem incompleta 1500-2000 - A experiência brasileira, São Paulo, Senac São Paulo Editora, 2000, p. 140.

${ }^{66}$ Junia Pereira Furtado, O Livro da Capa Verde. O Regimento Diamantino de 1771 e a Vida no Distrito Diamantino no Período da Real Extração, São Paulo, Annablume, 1996.
} 
terísticas da História Natural moderna, como o pragmatismo, o utilitarismo, o ecletismo, entre outras, estavam presentes nas suas dissertações. Além disso, observa-se a sua inserção no conjunto das práticas científicas mineralógicas no período entre o final do século XVIII e o início do XIX, tanto pelos termos que empregava, como pela sua postura teórico-metodológica, que buscava descrever os minerais em seu local de ocorrência, dando aos seus estudos um caráter nitidamente geográfico, em que o trabalho de campo adquiria papel de relevância. Portanto, o estudioso seguia os caminhos próprios de sua ciência, no estágio em que se encontrava naquele período.

Naturalista ligado aos interesses do Estado português, teve uma participação ativa no projeto reformista político-científico do governo mariano. Durante a sua trajetória de vida em Portugal, os estudos científicos e os interesses políticos caminharam lado a lado, numa íntima e inseparável associação. Ele colocou os conhecimentos científicos adquiridos no campo da História Natural, sobretudo os relacionados à mineralogia, em prol da regeneração da nação portuguesa. Membro de uma elite esclarecida e atualizada com o que de mais moderno se passava no restante da Europa além-Pirineus, acreditava que a ciência teria um papel fundamental para a realização concreta e efetiva do programa de reformas que visava conservar a integridade do Império português. 